\title{
The Epidemic of Mental Health in Higher Education and Its Impact on Students' Academic Success
}

\author{
Regina Enwefa, Stephen Enwefa, Gabriel Fagbeyiro \\ Southern University and A \& M College, USA
}

\begin{abstract}
There are over twenty million students who are enrolled in American colleges and universities, at least four out of ten of these students identify themselves as a diverse student. All college students face a multitude of challenges such as academic pressures, including social, emotional, and financial. Many diverse students who are international and attend college at American universities will more than often experience enormous causes of psychological distress compared to their peers. Some of the factors that impose on these students are discrimination, stigma, cultural mistrust, imposterism, and most of all the feelings of isolation that definitely impact their emotional and mental well being for being a diverse student. Over the past decades, it can be agreed upon that there is a health crisis on our college campuses. Mental illness is on the rise around the world in higher education. The numbers of students with mental health illness is increasing in numbers and also severity. Indeed, there is an epidemic of mental health illness across institutions of higher learning and institutions also are facing a substantial challenge in meeting the needs of students, faculty, and staff. Mental health disorders can be accounted for approximately half of the disease amongst students in higher education. The college years are supposed to be one of the best experiences that students will remember as they transition further into adulthood. However, the college years can be challenging and will definitely have an impact on academic success. Higher education institutions provide opportunities to address one of the most significant public health crisis within a lifetime for adolescents and adults. This study examined the role of mental health in higher education and its impact on academic student success.
\end{abstract}

\section{Introduction}

Mental Health can be defined as a state of well being in which as individual realizes his or her potential, coping skills along with normal life stressors in life. [1] defines mental health as a state of complete physical, mental, and social well being. Mental health is important to the conceptual foundation of human beings to process, interact with one another, work, think, and most of all enjoy life. The restoration for mental health must always be regarded as a vital part of life and concern for communities, and global societies.

According to the American with Disabilities Act 1990 (ADA) this includes people with mental illness who may meet one of three definitions:

1) A physical mental impairment that limits one or more major life activities of an individual.

2) A record of such an impairment

3) Being regarded as having such an impairment.

The ADA defines mental health as any mental or psychological disorder such as emotional or mental illness, specific learning disabilities, mental retardation, and organic brain syndrome. Based on the definitions, mental health is considered to be an assiduous psychological or psychiatric disorder, emotional and/or mental illness that affects academic performance. Mental health is listed in the American Psychiatric Association Diagnostic and Statistical Manual, the American with Disabilities Act (ADA), and the International Classification of Diseases (ICD). These organizations imply that the mental illness interferes with major life activity and causes a functional limitation within the educational setting.

All college graduates can reflect back to their experiences when they first went to college. It may have been stressful to some and for others it simply was a process of growing up. Students are faced with having to deal with a multitude of things such as academic pressure, separation from their family, having to work and support their families that leads to serious complex responsibilities. [2] stress is a fact of life for students attending college. There are growing numbers of students who arrive on college campus with a history of significant mental health issues. Many of these students are actually being administered psychiatric medications than ever before at higher levels. Students attending college are also coping with friendships, relationships, distance from home and family that periods of adjustment. Many students often feel overwhelmed, anxious, isolated, and at times hopeless. A combination of all of these 
stressors can mentally, psychologically, physically, and spiritually disrupt academic performance and lead to dysfunction in coping in life [2]. Being able to know the warning signs of trouble early, how to respond, will greatly increase the ability for college professors to help improve the quality of life, and most of all, maybe even save a life.

Mental health problems have become common among college students. This may be due to financial constraints, lack of state funding, diversity, income, denial, inadequate treatment of the actual mental health issue, substance use/abuse, psychotropic medications, traditional vs. historically black colleges and universities, disability, age, and maturity are just some of the common burdens affecting college students in higher education. Many of the mental health disorders experienced by students receive their peak onset during young adulthood. A majority of mental health disorders have onset before the age of 24 , this is approximately the age many are in higher education according to [3].

Due to social media and recognition of mental health issues, the number of students with mental health problems entering college is on the rise. Socioeconomic pressures are recognized risks to mental health for individuals and their communities. Some examples of these would be poverty, lack of education, stressful conditions, discrimination, unhealthy lifestyle, and human rights violations. There are also some biological and genetic factors that contribute to the causes of mental health problems. As of a result of this increase, there is a necessity for counseling centers to be in high demand in meeting the needs of college students on campus. The percentage of students seeking support for mental health while attending college is forever increasing, however, many are not receiving the needed treatment due to the lack of funding. It is imperative to have strong mental health programs to support institutions to alleviate stress, suicide rates, substance abuse and many other mental health disorders.

Globally, over the past ten years there has been an increased demand for mental health programs and services for institution of higher learning. In view of the challenges being faced by universities across the globe many are being forced to develop programs for prevention and intervention. Universities are struggling to meet the demands and needs for mental health on their campus due to lack of training, knowledge and awareness, insufficient training, policies and procedures [4]. Research on college campuses for mental health issues has lacked the appropriate training, funding and information is scarce. Many students are being placed on waiting lists for the services due to a high demand for the services and also because of not having enough staff to meet the needs of the students on campus. The U.S. Department of Education, Office of Civil Rights (OCR) has not provided the needed guidance as to how colleges handle students that pose threats to to themselves and others. There are plethora of provisions and restrictions for federal financial aid that impacts the students' ability with mental health issues to complete their prospected programs.

\section{Demographics of Mental Health on College Campus}

Historically college students' mental health concerns stem from transition issues, homesickness, and detachment from family just to mention a few. These experiences are happening with all students regardless of ethnicity, race, and gender. Some are found to be quite complex and others are significant. [5] reported staggering results as to how students felt while in college. Anxiety was one of the most reported concern among college students roughly $56.9 \%$.

At least $33.4 \%$ of students have been taking psychotropic medication by the time they entered the university. [6] indicated that $64 \%$ of students no longer in college report that they were not attending college because of mental health related reasons. In 2009, there were approximately 21.4 million college students within the United States. 15.0 million college students were white, 2.8 million were black/African American, 2.4. million were Hispanic/Latino, and 1.2 million were from Asian cultures respectfully. These numbers are of critical importance because they signify that there is much work to do done specifically relating to cultural diversity and underrepresented populations underutilizing services available to them on their college campuses. Some possible barriers for accessing campus support services may include one or all of the following: cultural background, distrust, spirituality, and cultural factors. Another important obstacle is institutional hurdles such as lack of awareness and expectation for assistance, lack of services in their high schools, denial of their disability or psychological disorder and competition. Each student comes to the college campus with a different perspective to academic success [7].

\section{Prevalence and Incidence of Students with Mental Health Disorders on College Campuses}

The percentage of students seeking support for mental health services while attending college has increased within the last three years. Many students who do not receive the necessary support for their mental health needs will become dropouts, and have lower grade point average (GPA). The amount of people going to college today has increased. The amount of nontraditional students on campus such as first generation students, veterans, and international students has grown significantly. Many of these students face prejudice, racism, under education, and 
acculturation. For some of these students, college is their first time living independently and alone. The Healthy Minds study conducted a survey of over 16,000 college students on more than 100 campuses at large attempting to determine students who are likely to have mental disorder and also wanted to know if these students had previously received an evaluation. The study reported that at least six percent of undergraduate students has at one point of time considered suicide [8]. Anxiety disorders has been found to be one of the most prevalent psychiatric challenges among college students [8]. [8] observed that at least 11.9 percent of college students suffer from an anxiety disorder. Another common mental health problem among college students would be depression with prevalence rates of at least 7 to 9 percent. [8] reported that over half of all cases of depression had the first onset during childhood, adolescence, or either into young adulthood. Suicide is the third leading cause of death among young adults and is an immense problem for college students. Depression, substance abuse, and hopelessness are among the major risk factors to consider for suicide for the college wide age group. Eating disorders and Attention-Deficit/Hyperactivity Disorder (ADHD) begins during childhood but often persists into adulthood. College students with ADHD diagnosis often exhibit poor academic performance, social difficulties, and some substance abuse use while in college that can have a detrimental affect on academic success. Autism spectrum disorders (ASDs) includes a complex and chronic neurodevelopmental disorder that exhibits deficits in socialization, communication, poor academic success, and behavior. Lastly, substance abuse such as alcohol and drugs are quite prevalent during the college years and have been found to be the most prevalent problem among college students. Alcohol consumption among college students can be related to accidental injuries, unsafe sex, sexual assaults, and poor classroom performance.

\section{Improved Academic Student Performance and Success}

There are five different stress related factors that impact college life which over time can impact academic success of students. There are many academic signs to consider that can interrupt the rigor of student's academic success. Some of these include: repeated absences from class, lab, missed assignments, exams and appointments. Professors are able to notice a decline in the quality and quantity of work, extreme disorganization or erratic behavior, social isolation, despairs, confusion, excessive procrastination, excessively anxious behavior while called upon in class, continual seeking of special provisions such as extra time for deadlines, make-upexams, or even an extension on a paper, patterns of perfectionism (Can't accept themselves if they don't get an A or outburst in class that they must obtain an A), overblown response aloud in the class in response to grades and other scored assignments.

\section{Behavioral and Emotional Triggers}

There are many triggers that can impact academic success for students with mental illness. You may find these students angry most of the time or exhibit hostile outburst, yelling, and aggressive comments in class, unusual withdrawal behavior, swollen or red eyes, change in mood, difficulty concentrating, crying and tearfulness at times in and out of class, irritability, excessively demanding or dependent behavior, observable shakiness, tremors, fidgeting and pacing in and out of the classroom. All of these may be attributed to basic life distress, grief and loss, family conflict, and economic hardships.

If students are provided that individualized support this can lead to increased retention, increased GPA, and graduation rates overtime. This would propose that students who cannot meet academic expectations the colleges can interactively engage students for on-campus interventions to assist with some of the underlying problems.

\section{Accessibility and Confidentiality, Policies for Students with Mental Health Issues on Campus}

There are two key points that need attention: access and services. Services available to students who need it, nothing else can correct that. There is a need for training for faculty and staff in this area: an increase in mental health awareness, training on ADA requirements, development of an identification and referral program for students who are in crisis mode so that they can be provided access and services.

There are many policies that have been developed to better meet the needs of the student. Some suggestions that can be beneficial to students are:

1) Allow students the opportunity to take reduced credit course load.

2) Extend the degree completion timelines, offer extensions if needed as part of an amendment to the Higher Education Act. This would allow students the opportunities to have additional semesters of financial aid to retain their various grants beyond semesters because of their disabilities.

3) Improve the federal guidelines for financial aid for mental health.

4) Offer flexible guidelines for assignments.

5) Implementing universal design for learning in the classroom and campus community.

6) Have staff to be as diverse as the student body. 
7) Substance Abuse and Mental Health Services Administration (SAMHSA) should implement actions to increase mental health programs on college campuses and provide opportunity for funding.

\section{Modifications and Accommodations to Students with Mental Illness}

There are two basic federal laws that must be applied to students with disabilities: 1) Section 504 of the Rehabilitation Act of 1973 and 2) the Americans with Disabilities Act of 1990 (ADA) [9]. Section 504 prevents students from being discriminated against because of a disability [9]. In contrast, ADA is required by both private and public colleges and universities to provide equal access to students with disabilities. There must be reasonable modifications in policies, practices, and procedures in order to avoid any actions against a student because of a disability. Based on ADA and Section 504, all colleges must provide students with disabilities reasonable and appropriate modifications to their policies and practices campus wide. Modifications should be individualized and on a case by case basis. Below are some suggested flexibilities:

- Flexible class schedule

- Rewards for attendance

- Emotional Support Animals

- Universal Design for Learning

- Create a safe and discreet venue where students access services

- Diverse list of services available such as: inperson, online, telephone, chat, and Facebook

There are some laws that protect the student's privacy that must be abided by. [10] limits the disclosure of information from student education records. The Family Educational Rights and Privacy Act (FERPA) applies to all colleges receiving federal funds [10]. That includes all virtual records maintained by higher education institutions. FERPA only applies to student education records and not to personal knowledge derived directly from the student or personal experience with a student. College officials are able to disclose information about a student to school officials who have the legitimate interests in the information about the student. FERPA does not permit a parent right to access information about a student educational records. It is up to the university to release information to parents, police and others if deemed necessary.

The Health Insurance Portability and Accountability Act (HIPAA) is one of the primary policy with administrative simplification provisions [11]. It was enacted to improve the efficiency and effectiveness of the United States Healthcare System. One major goal of HIPAA was to establish national standards for protecting medical records and other personal health information. HIPAA privacy rules does not apply to student treatment records created on campus, whether they are shared with others or used solely for treatment. The confidentiality of these records is protected under federal and state medical confidentiality and disability laws. Student medical or mental health records are created solely for the purpose of treatment for health and counseling center and only shared with those directly involved in treatment.

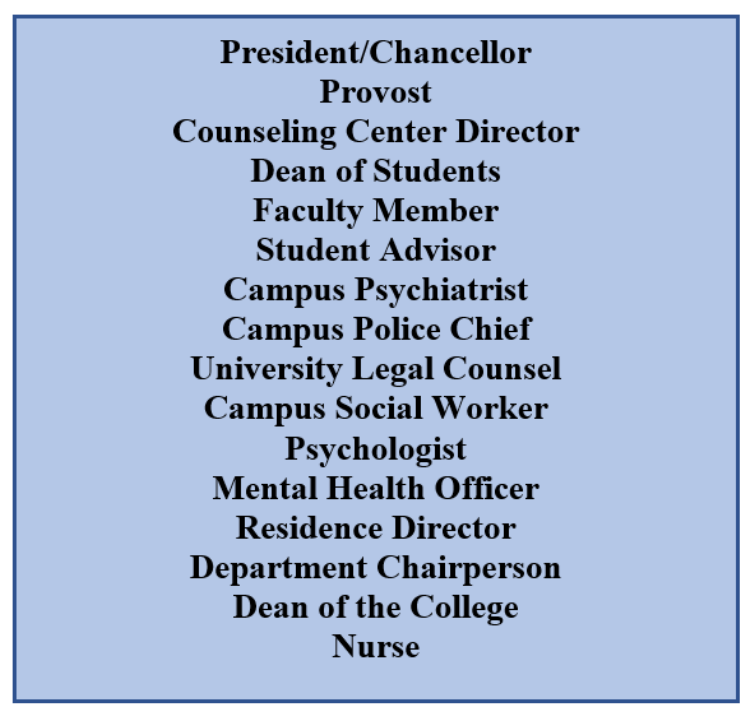

Figure 1. Members of Campus Mental Health Team

This campus wide team of support should meet regularly to discuss growing concerns/threats in order to be able to act when an active threat is identified. All students must be treated fairly at all times. Social media use can be an effective tool for communication across the entire campus community about a particular situation if there ever is a need.

\section{Conclusion}

Over the past twenty years, college and universities have been able to be a witness to the rise of mental health issues on their campuses. The increase of mental health was brought on by some of the campus tragedies such as VA Tech, Northern Illinois University, and the University of Alabama at Huntsville. Today, institutions of higher learning are doing everything they can to prevent any future occurrences from ever happening again. It is imperative that colleges and universities make their campuses safe.

The United States government should be willing to fully fund Section 9031 of the $21^{\text {st }}$ Century Cures Act to increase individuals with mental health and substance disorders addressing the need for mental health services and support. Mental health problems are on the rise among college students. Academic 
pressure and expectancies with stressors together, may precipitate the first onset of mental health problems or symptoms. There is a need for colleges to develop websites that include more of a comprehensive and updated approach to mental health issues. It is necessary to engage in professional development for mental health awareness training for faculty and staff. This information can be provided during campus orientation, campus tours, hosting mental health campus wide events, initiate social activities on mental health in dormitories. Additionally, provide promotional and post promotional materials with information about mental health through campus social media. Faculty may provide screening tools within their course syllabi in order to link students to the resources they would need. Warning signs of mental health issues and what to do about them would be helpful if all students receive a course syllabus that can contain adequate information, videos/links, resources on dealing with stress, bullying, loneliness, and other pertinent issues. There is a need to also coordinate with everyone involved in students' care, including on and off campus providers, provide support for veterans, and offer peer support services. Institutional change is needed in order to promote mental health diversity on college campuses globally. Also, the campus environment has to shift to better meet the needs of all students. The millennial generation should be included due to their widespread use of technology. At least one out of five college students begin using the computer at around the age of five and seven. What does this mean for institutions of higher learning? It is imperative for colleges and universities to place mental health at the forefront for faculty, staff, and students top priority. Recognizing the problem of mental health does exist and committing to the establishment of supportive measures to address the issue is a very important step. Furthermore, ascertaining the ever changing demographics of the student body and ensuring that there are effective policies in place to assist any student who may need help when a crisis arises. There is a necessity to consider all contributing factors for mental health including mobile phone use, online pornography, and pathological internet users ought to be identified as institutions move toward better services for students with mental illness. The determining factor will remain complex. More must be done and can be done. Seeking funding for mental health programming would be a big help towards meeting the needs of students and will lead to academic success. This must be given a priority in order to ensure safety and well being for all students. Taking on mental health should not rest upon only the counseling centers on campuses, but it should be an entire campus community that is committed and willing to increase awareness by establishing collaborative partnerships designed to minimize the possibility of future acts of campus violence.

\section{References}

[1] Mental health: a state of well-being. World Health Organization, accessed March 22, 2017, http://www.who. int/features/factfiles/mental_health/en/.

[2] Enwefa, S, and Enwefa, R (2014). Mental Health Disorders in Speech-Language-Pathology. Paper presented at the Mississippi Speech-Language-Hearing Association Annual Continuing Education Conference, Jackson, Mississippi.

[3] Kessler RC, Angermeyer M, Anthony JC, DE Graaf R, Demyttenaere K, Gasquet I, DE Girolamo G, Gluzman S, Gureje O, Haro JM, Kawakami, N, Karam, A, Levinson, D, Medina M, Oakley Browne, MA, Posada-Villa, Stein, DJ, Adley, Tsang CH, Aguilar-Gaxiola, S, Alonso, J, Lee, S, Heerings, S, Pennell, BE, Berglund, P, Gruber, MJ, Petukhova, M, Chatterji, S, and Ustun, TB. (2007). Lifetime Prevalence and Age-Of-Onset Distributions of Mental Disorders in the World Health Organization's World Mental Health Survey Initiative. World Psychiatry 6:168-176.

[4] Watkins, DC, Hunt, JB, Eisenberg, D. (2012). Increased demand for mental health services on college campuses: Perspectives from administrators. Qualitative Social Work. 11 (3): 319-337.

[5] National College Health Assessment 2015 Annual Report sponsored by the American College Health Assessment (ACHA-NCHA).

[6] Center for Collegiate Mental Health (CCMH) 2015 Annual Report. Publication No. STA 15-10.

[7] Schwartz, V., Kay, J. (2009). The crisis in college and university mental health. Psychiatric Times. 26 (1): 32-32.

[8] Kessler, Aminger, Aguilar-Gaxiola, Alonso, Lee, and Ustün, 2007. Age of onset of mental disorders: A review of recent literature. Curr Opin Psychiatry 20 (4): 359-364.

[9] Pub. L. 93-112, 87 Stat. 394 (29 U.S.C. 794), as amended

[10] The Family Educational Rights and Privacy Act (FERPA) (20 U.S.C. $§ 1232 \mathrm{~g}$; 34 CFR Part 99). (2017). US Department of Education, Washington, DC.

[11] The Health Insurance Portability and Accountability Act of 1996 (HIPAA), Public Law 104-191, Sections 261 through 264 of HIPAA. U.S Department of Health \& Human Services, Washington, DC. 